\title{
ADAPTIVE SELF-TUNING FUZZY BACKSTEPPING CONTROLLER FOR THE CONTROL OF ELECTRIC VEHICLE WITH TWO-MOTOR-WHEEL DRIVE
}

\author{
Ahmed LAGUIDI, Abdeldjebar HAZZAB, Othmane BOUGHAZI, Mohamed HABBAB \\ Laboratoire de Recherche Commande, Analyse et Optimisation des Systèmes Electro- énergétiques, université TAHRI Mohamed de \\ Bechar, BP 417, Bechar (08000), ALGERIA
}

\begin{abstract}
In this work we proposed a backstepping controller adapted by a fuzzy inference for the control of the electric vehicle with two motor wheel drives. This proposed combine controller has significantly improved control performance compared to conventional backstepping. The different speeds of the wheels are ensured by the electronic differential, this driving process makes it possible to direct each driving wheel to any curve separately. Modeling and simulation are performed using the Matlab / Simulink tool to study the performance of the proposed controller.
\end{abstract}

Keywords: Fuzzy logic, Backstepping controller, Electrical vehicle, Electronic differential, Adaptive control.

\section{INTRODUCTION}

Electric vehicles (EV) are developing fast during this decade due to drastic issues on the protection of environment and the shortage of energy sources, so new technologies allow the development of electric vehicles (EV) by means of electric motors associated with static converters [1]. As the environmental pollution and energy shortage is increasing, the electric car technology gets more and more attention by the government and academia. The electric vehicle technology research has become a hot spot of research at home and abroad. The electric vehicle drive control strategy research has become an important research direction. At present the electric cars are mainly divided into two drive forms including centralized drive and distributed drive. Compared with the centralized drive form, the distributed driving form omits the traditional mechanical structure, shortens the transmission chain and improves the transmission efficiency greatly. Each driving wheel of distributed driving vehicle could be controlled independently. The directly yawing moment control, electronic differential control, anti-slip regulation (ASR) and other advanced control could be achieved by controlling each wheel coordinately. It is therefore very necessary to design a vehicle control system with high performance, easy implementation and low cost. Backstepping is a systematic and recursive design methodology for nonlinear feedback control. The backstepping design alleviates some limitations of other approaches (Kanellakopoulos et al, 1991; Krstic et al., 1995; Benaskeur, 2000; Lin and Lee, 2000; Waiet al; 2001; Pozo et al, 2008) $[8,9,10,11,12]$. The idea of backstepping design is to select recursively some appropriate functions of state variables as pseudo-control inputs for lower dimension subsystems of the overall system. Each backstepping stage results into a new pseudo-control design, expressed in terms of the pseudo-control designs from the preceding design stages. When the procedure terminates, a feedback design for the true control input results and achieves the original design objective by virtue of a Lyapunov function, which is formed by summing up the Lyapunov functions associated with each individual design stage. An adaptive robust nonlinear controller can be derived using this control method in a straightforward manner (Kanellakopoulosetal., 1991; Krstic et al., 1995; Benaskeur, 2000; Pozoet al, 2008) [8,9,10,11]. Recently, the newly developed adaptive backstepping technique has been used in the design of speed controllers for DC, induction motors and permanent magnet motors (Lin and Lee, 2000; Waiet al, 2001; Huang et al., 2002 Derdiyok, M. K. Guven, H. Rahman, N. Inane, L. Xu, Oct. 2002 and F. Khoucha, K. Marouani, A. Kheloui, K. Aliouane, June $2004[12,13,14,15,16]$. In this paper we proposed a novel design of the backstepping controller adapted by a fuzzy inference for the control of the electric vehicle with two motor wheel drives.

The remainder of this paper is organized as follows: The first part reviews the main components of the electric vehicle model. The second part shows the electronic differential and its implementation. Third part shows the development backstepping controller design for electric vehicle engines. Fourth part shows the model of fuzzybackstepping control law proposed. The proposed structure of the propulsion system studied is given in the fifth part. The sixth part gives simulation results of the different cases studied. Finally, the conclusion is drawn to the seventh parties.

\section{ELECTRIC VEHICLE MODEL}

Fig. 1 represents general diagram of an electric traction system using an asynchronous squirrel cage motors supplied by voltage inverter [3].

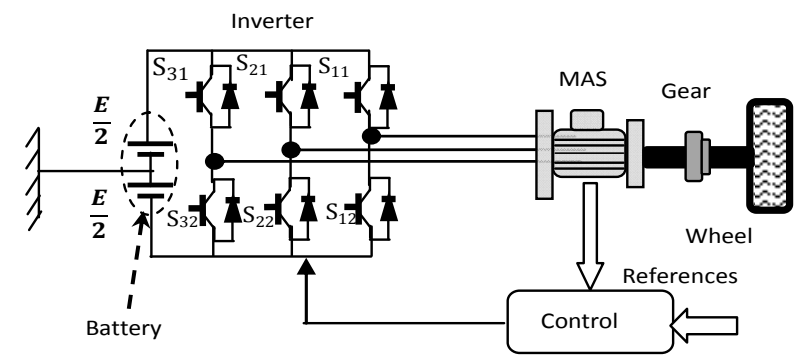

Fig. 1 Electrical traction chain

For the design presented in this paper it is considered that the two rear wheels of the vehicle are driven by asynchronous squirrel cage motors. 
The reduced nonlinear model of IM using the orientation of the rotor flux is given by the following equation system:

$\frac{d i_{d s}}{d t}=a_{1} i_{d s}+\omega_{s} \cdot i_{q s}+a_{2} \cdot \emptyset_{r}+b v_{d s}$

$\frac{d i_{\mathrm{qs}}}{\mathrm{dt}}=-\omega_{\mathrm{s}} \cdot \mathrm{i}_{\mathrm{ds}}+\mathrm{a}_{1} \mathrm{i}_{\mathrm{qs}}+\mathrm{a}_{3} \cdot \emptyset_{\mathrm{r}} \omega+\mathrm{bv}_{\mathrm{qs}}$

$\frac{\mathrm{d} \emptyset_{\mathrm{r}}}{\mathrm{dt}}=\mathrm{a}_{4} \cdot \mathrm{i}_{\mathrm{ds}}+\mathrm{a}_{5} \cdot \emptyset_{\mathrm{r}}$

$\frac{\mathrm{d} \omega}{\mathrm{dt}}=\frac{\mathrm{P}}{\mathrm{J}} \mathrm{a}_{6} \cdot\left(\mathrm{i}_{\mathrm{qs}} \cdot \emptyset_{\mathrm{r}}\right)+\mathrm{a}_{7} \cdot \omega+\mathrm{a}_{8} \cdot \mathrm{C}_{\mathrm{r}}$

Where:

$\mathrm{C}_{\mathrm{r}}-$ Load torque

$\mathrm{a}_{1}=\frac{1}{\sigma \mathrm{L}_{\mathrm{s}}}\left(-\mathrm{R}_{\mathrm{s}}-\left(\frac{\mathrm{L}_{\mathrm{m}}}{\mathrm{L}_{\mathrm{r}}}\right)^{2} \cdot \mathrm{R}_{\mathrm{r}}\right) ; \mathrm{a}_{2}=\frac{1}{\sigma \mathrm{C}}\left(\frac{\mathrm{L}_{\mathrm{m}} \cdot \mathrm{R}_{\mathrm{r}}}{\mathrm{L}_{\mathrm{r}}^{2}}\right) ;$

$\mathrm{a}_{3}=\frac{1}{\sigma \mathrm{L}_{\mathrm{s}}}\left(\frac{\mathrm{L}_{\mathrm{m}}}{\mathrm{L}_{\mathrm{r}}}\right) ; a_{4}=\left(\frac{L_{m} \cdot R_{r}}{L_{r}}\right) ; \mathrm{a}_{5}=\frac{\mathrm{R}_{\mathrm{r}}}{\mathrm{L}_{\mathrm{r}}} ; \mathrm{a}_{6}=\frac{\mathrm{P} \cdot \mathrm{L}_{\mathrm{m}}}{\mathrm{L}_{\mathrm{r}}} ; \mathrm{a}_{7}=\frac{\mathrm{f}_{\mathrm{c}}}{\mathrm{J}} ;$ $\mathrm{a}_{8}=\frac{\mathrm{P}}{\mathrm{J}}$

In this electric traction system, a two-stage inverter is used to obtain three balanced phases of alternating current with variable current frequency of the battery.

$\left[\begin{array}{c}\mathrm{v}_{\mathrm{a}} \\ \mathrm{v}_{\mathrm{b}} \\ \mathrm{v}_{\mathrm{c}}\end{array}\right]=\frac{\mathrm{U}_{\mathrm{dc}}}{3}\left[\begin{array}{ccc}2 & -1 & -1 \\ -1 & 2 & -1 \\ -1 & -1 & 2\end{array}\right]\left[\begin{array}{l}\mathrm{S}_{\mathrm{a}} \\ \mathrm{S}_{\mathrm{b}} \\ \mathrm{S}_{\mathrm{c}}\end{array}\right]$

Where:

$\mathrm{S}_{\mathrm{a}, \mathrm{b}, \mathrm{c}}$ - are logical switches obtained by comparing the control inverter signals with the modulation signal

The general scheme of the driving wheels control is represented by Fig. 2. It's an electric vehicle which the back driving wheels are controlled independently by two IM.

The reference blocks must provide the speed references of each motor taking into consideration information from the different sensors. [7]

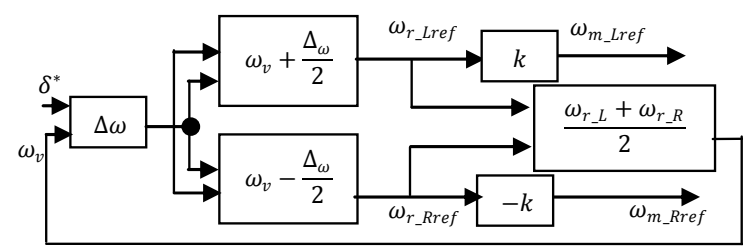

Fig. 2 Block diagram show use of the electronic differential

It is possible to determine the speed references according to the requirements of the driver. When the vehicle arrives at the beginning of a curve, the driver applies a curve angle on each driving wheels [17, 18].

The electronic differential acts immediately on the two motors reducing the driving wheel speed situated inside the curve, and increases the speed of the driving wheel situated out-side the curve. The driving wheels angular speeds are:

$\mathrm{w}_{\mathrm{mR}}^{*}=\frac{\mathrm{v}_{\mathrm{h}}}{\mathrm{R}_{\mathrm{r}}}+\mathrm{K}_{\mathrm{b}} \cdot \Delta \omega ; \mathrm{w}_{\mathrm{mL}}^{*}=\frac{\mathrm{v}_{\mathrm{h}}}{\mathrm{R}_{\mathrm{r}}}-\mathrm{K}_{\mathrm{b}} \cdot \Delta \omega$

The Fig. 3 represents the electric vehicle (EV) driving wheels system, where $M_{R}$ and $M_{L}$ represent the right driving motor and left driving motor respectively [7].

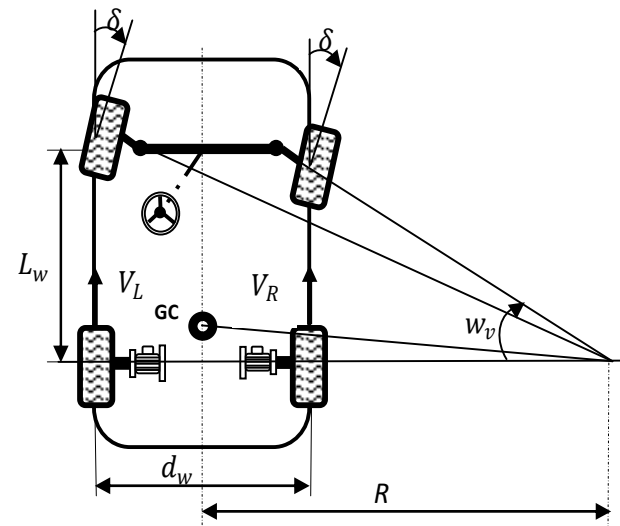

Fig. 3 Driving trajectory model

The driving wheels speed variation is imposed by the trajectory desired by the driver and it's given by:

$\Delta \omega=\frac{d_{w}}{2} \cdot \frac{\sin (\delta+\beta)}{l_{w} \cdot \cos \delta} \cdot \frac{V_{h}}{R_{r}}$

where:

$\mathrm{V}_{\mathrm{h}}$ - tangential velocity of the vehicle

$\mathrm{K}_{\mathrm{b}}$ - choice of direction coefficient

$\mathrm{R}_{\mathrm{r}}$ - diameter of the wheel

\section{BACKSTEPPING CONTROL}

The foundation of backstepping is the identification of virtual control variable and forcing it to become a stabilizing function. Thus, it generates a corresponding error variable which can be stabilized by proper input selection via Lyapunov's stability theory (Kanellakopoulos et al., 1991; Krstic et al., 1995; Lin and Lee, 2000; Wai et al., 2001; Huanget al., 2002). The backstepping technique can be perfectly applied for nonlinear system (Benaskeur, 2000; Pozoet al, 2008).

$\mathrm{e}_{1}=\omega^{*}-\omega$

Deriving equation (8) term by term, we obtain

$\dot{\mathrm{e}}_{1}=\dot{\omega}^{*}-\left(\frac{\mathrm{P}}{\mathrm{J}} \mathrm{a}_{6} \cdot \mathrm{i}_{\mathrm{qs}} \cdot \emptyset_{\mathrm{r}}+\mathrm{a}_{7} \cdot \omega+\mathrm{a}_{8} \cdot \mathrm{C}_{\mathrm{r}}\right)$

We choose $\mathrm{i}_{\mathrm{qs}}^{*}$ as our first virtual command, the stabilizing function is chosen as follows:

$\mathrm{i}_{\mathrm{qs}}^{*}=\frac{1}{\mathrm{a}_{6} \emptyset_{\mathrm{r}}}\left(\dot{\omega}^{*}-\mathrm{a}_{7} \omega-\mathrm{a}_{8} \mathrm{C}_{\mathrm{r}}-\mathrm{c}_{1} \mathrm{e}_{1}\right)$

Replacing (10) in (9) so the derivative error is:

$\dot{\mathrm{V}}\left(\mathrm{e}_{1}\right)=-\mathrm{c}_{1} \cdot \mathrm{e}_{1}^{2} \leq 0$

Where:

$\dot{\mathrm{V}}\left(\mathrm{e}_{1}\right)$ - The function of Lyapunov

$\mathrm{c}_{1}$ - Backstepping Controller Adjustment Coefficient

Since $\mathrm{i}_{\mathrm{qs}}^{*}$ is not an input control of the system to be adjusted, an error variable $\dot{e}_{2}$ is chosen to display the input command $\mathrm{v}_{\mathrm{qs}}^{*}$. 


\subsection{Case of straight way}

Flat road with $10 \%$ slope at $60 \mathrm{~km} / \mathrm{h}$ speed: In this test, the system is submitted to the same speed reference. The driving wheels speeds stay always the same and the road slope does not affect the control of the wheel and the Backstepping control act immediately on the speed loop's and rejects the disturbance and give's more and more efficiency to the electronic differential output references. We can say the slope sensitize the motorization to develop efforts in order to satisfy the electric traction chain demand. The system behavior of these speeds is illustrated by Fig.4; Fig. 6 describe the electromagnetic Torque variations. It seemshas the two motors develop the same efforts in order to pass the slope The resistant torques is shown in Fig. 5.

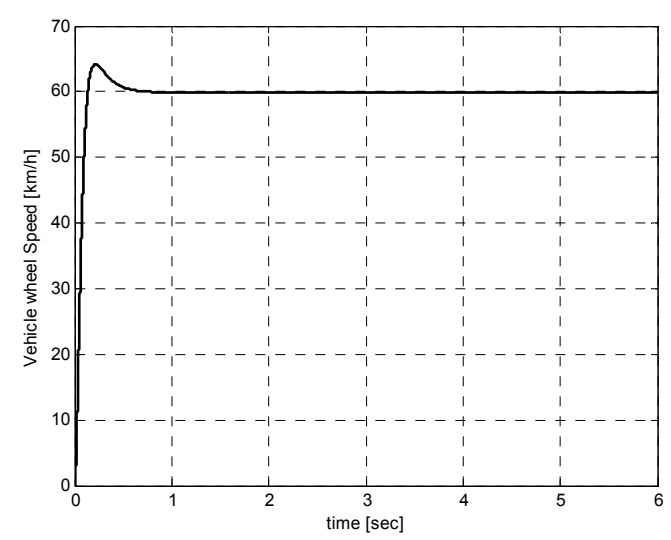

Fig. 4 Vehicle wheel speed

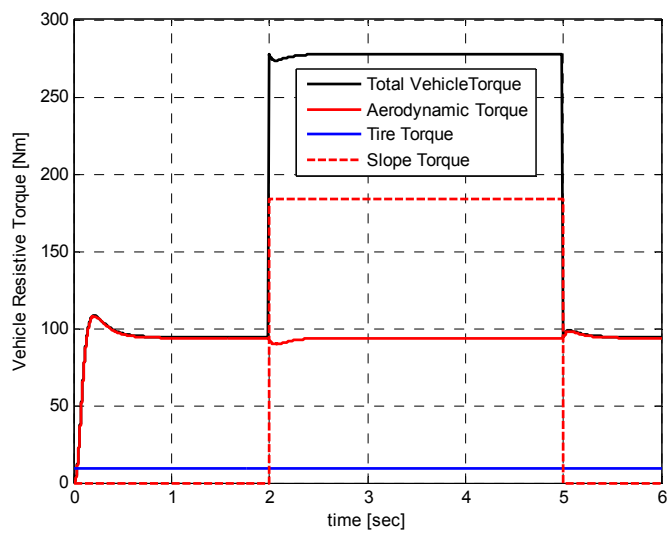

Fig. 5 Resistive Torques

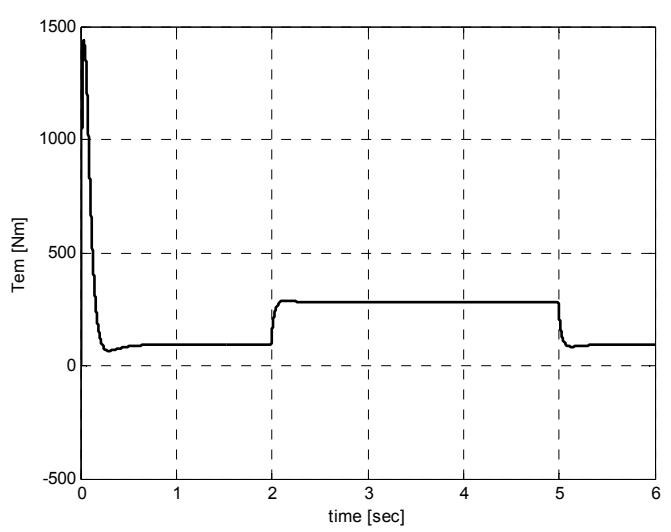

Fig. 6 Motor Electromagnetic Torque

\subsection{Case of curved way}

Curved road at right side with speed of $60 \mathrm{~km} / \mathrm{h}$ : The vehicle is driving on a curved road on the right side with $60 \mathrm{~km} / \mathrm{h}$ speed. The assumption is that the two motors are not disturbed. In this case the driving wheels follow different paths, and they turn in the same direction but with different speeds. The electronic differential acts on the two motor speeds by decreasing the speed of the driving wheel on the right side situated inside the curve, and on the other hand by increasing the wheel motor speed in the external side of the curve. The Backstepping control ensure the stability of the propulsion system by maintaining the motorization error speed equal zeros and gives a good rising time and no over tracking error too The behavior of these speeds is given by Fig. 9, the variation of the vehicle torques and the electromagnetic torques are illustrated in Fig. 7 and Fig. 8.

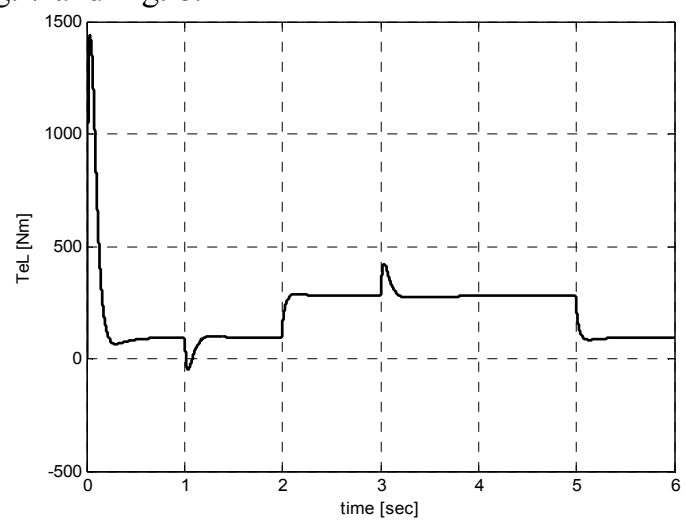

Fig. 7 Left motor Electromagnetic Torque

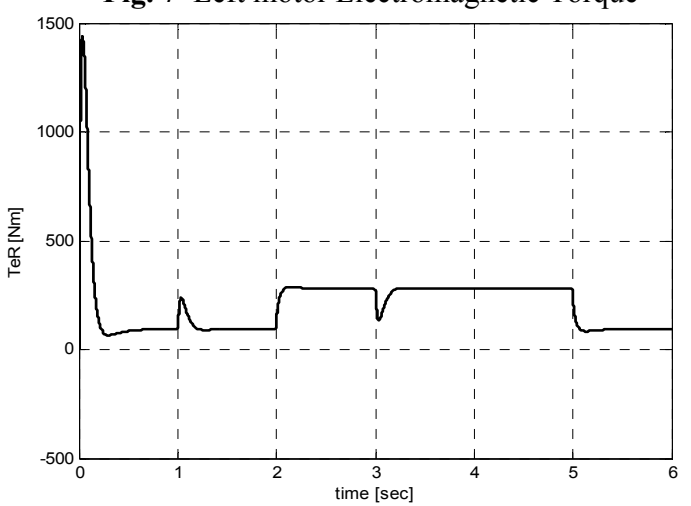

Fig. 8 Right motor Electromagnetic Torque

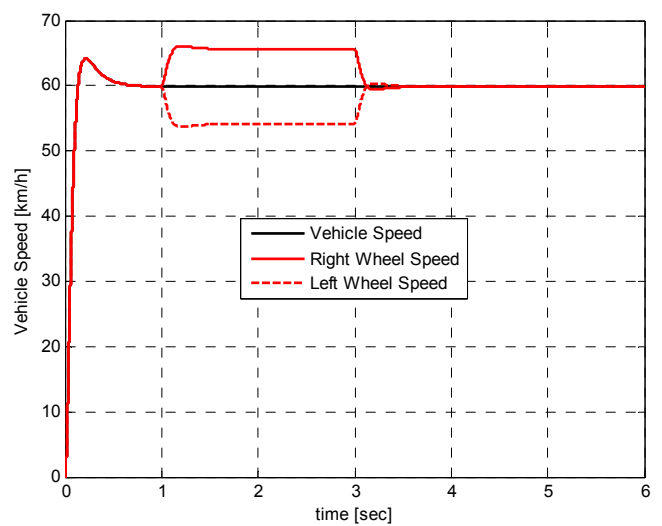

Fig. 9 Vehicle speed in right turn in curved way 


\section{FUZZY BACKSTEPPING CONTROL}

In this section, Fuzzy-backstepping controller is developed, in which a fuzzy inference mechanism is used to generate the control law parameters. The proposed Fuzzy-backstepping controller scheme for EV speed control is shown in Fig. 10

$$
\mathrm{i}_{\mathrm{qs}}^{*}=\frac{1}{\mathrm{a}_{6} \emptyset_{\mathrm{r}}}\left(\dot{\omega}^{*}-\mathrm{a}_{7} \omega-\mathrm{a}_{8} \mathrm{C}_{\mathrm{r}}-\mathrm{c}_{1} \mathrm{e}_{1}\right)
$$

The resulting fuzzy inference rules for the output variable $\alpha$ of as follows:

Rule 1: if $e \mathrm{~N}$ and $\dot{\mathrm{e}} \mathrm{N}$ then $\alpha$ is $\mathrm{VB}$;Rule 2: if $e \mathrm{~N}$ and $\dot{\mathrm{e}}$ $\mathrm{MN}$ then $\alpha$ is $\mathrm{VB}$; Rule 3 : if $e \mathrm{~N}$ and $\mathrm{e} \mathrm{Z}$ then $\alpha$ is $\mathrm{MB}$; Rule 4: if $e \mathrm{~N}$ and $\dot{\mathrm{e}} \mathrm{MP}$ then $\alpha$ is MS ; Rule 5: if $e \mathrm{~N}$ and $\dot{\mathrm{e}} \mathrm{P}$ then $\alpha$ is VS

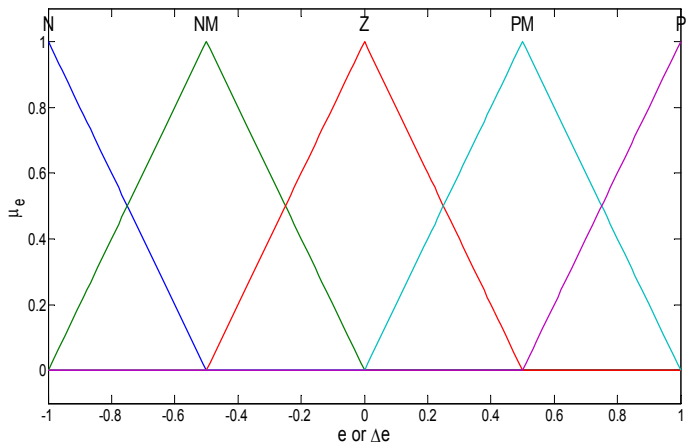

Fig. 10 The inpute or $\Delta e$ membership function

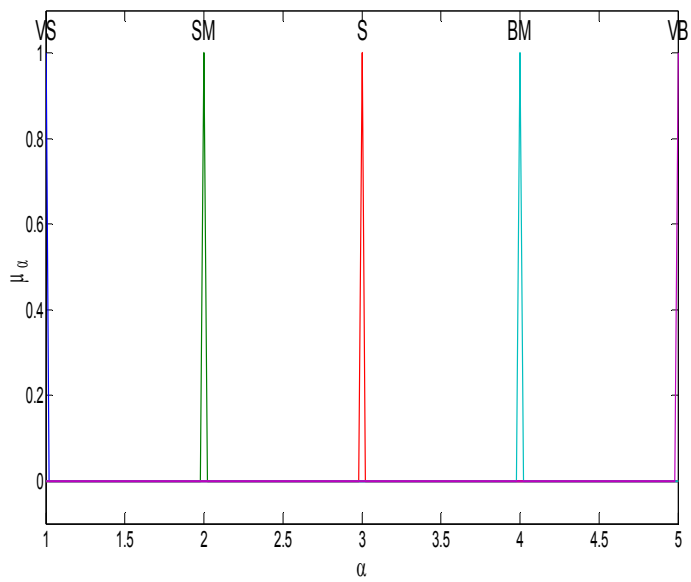

Fig. 11 The output $\alpha$, membership function

Table 1 Fuzzy rule base

$\begin{array}{cccccc}e & \text { N } & \text { NM } & \text { Z } & \text { PM } & \text { P } \\ \Delta e & & & & & \\ \text { N } & \text { BM } & \text { SM } & \text { VS } & \text { S } & \text { VB } \\ \text { NM } & \text { BM } & \text { SM } & \text { VS } & \text { S } & \text { VB } \\ \text { Z } & \text { BM } & \text { SM } & \text { VS } & \text { S } & \text { VB } \\ \text { PM } & \text { SM } & \text { VS } & \text { S } & \text { S } & \text { VB } \\ \text { P } & \text { SM } & \text { VS } & \text { S } & \text { VB } & \text { VB }\end{array}$

The principle of adjusting the speed of the EV by a fuzzy backstraping controller is presented by a block diagram as shown in Fig. 12.

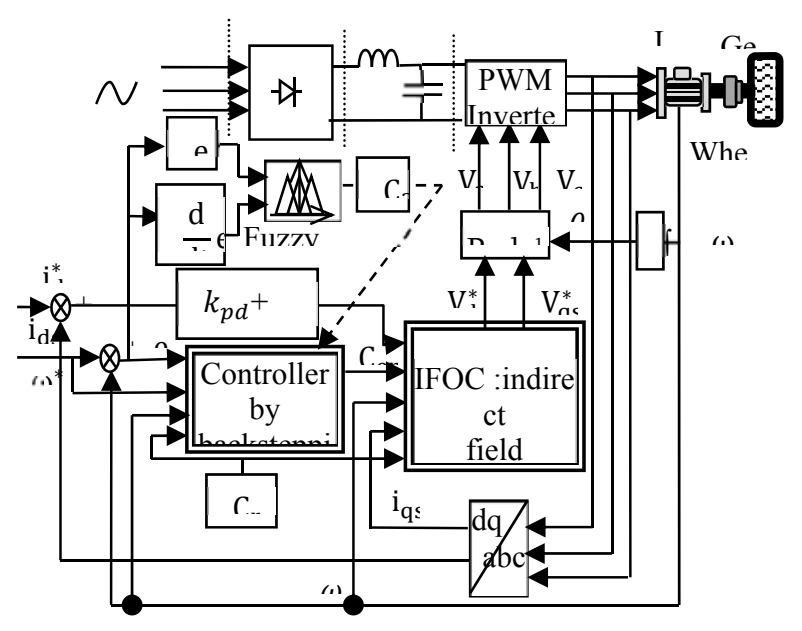

Fig. 12 Block diagram of the speed adjustment of EV by controller fuzzy backstepping

The simulation tests in the case of straight way and curved way are the same used with Backstepping controller the results of the simulation are presented in the figures 13, 14, $15,16,17$ and 18 .

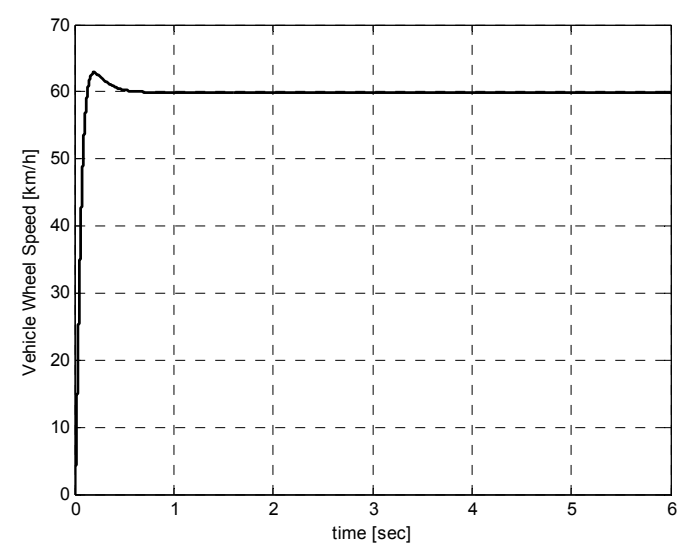

Fig. 13 Vehicle wheel speed

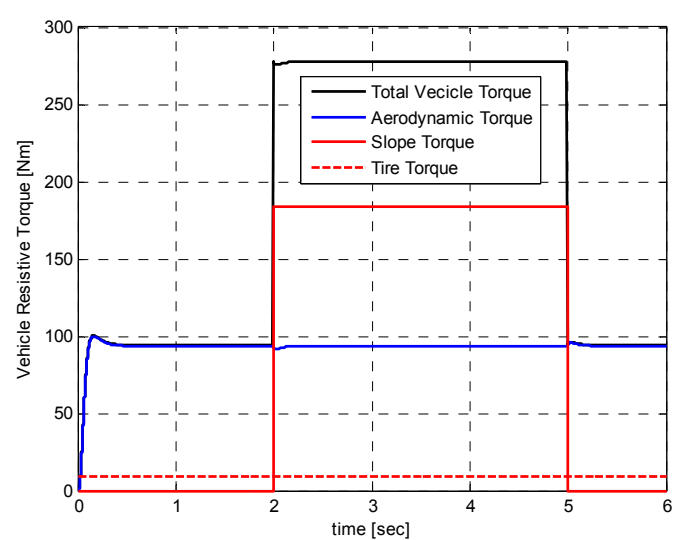

Fig. 14 Resistive Torques 


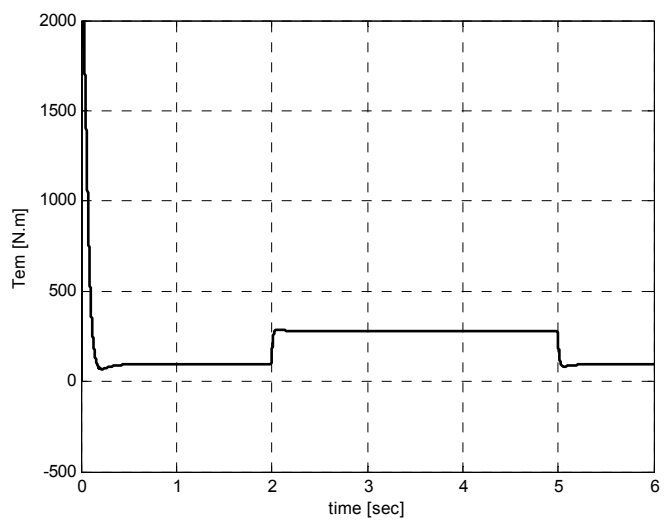

Fig. 15 Motor Electromagnetic Torque

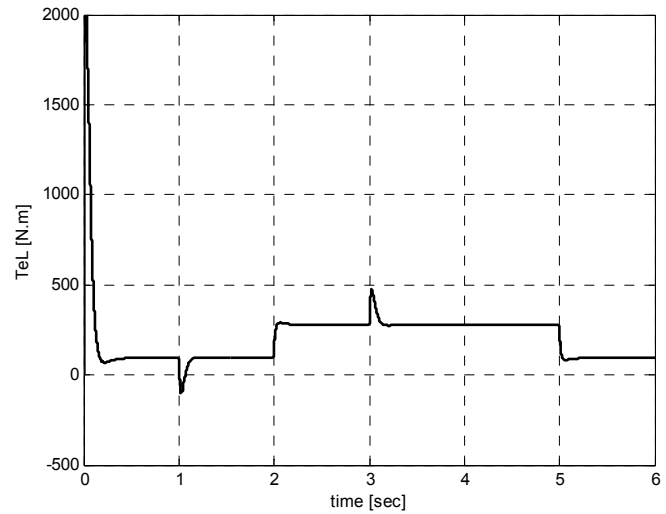

Fig. 16 Left motor Electromagnetic Torque

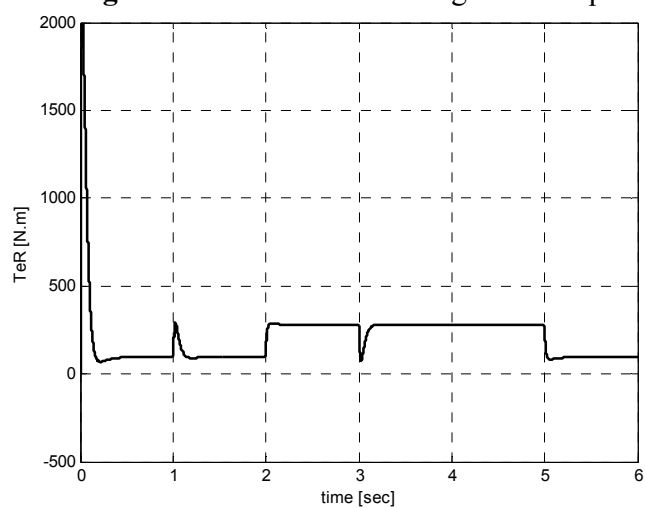

Fig. 17 Right motor Electromagnetic Torque

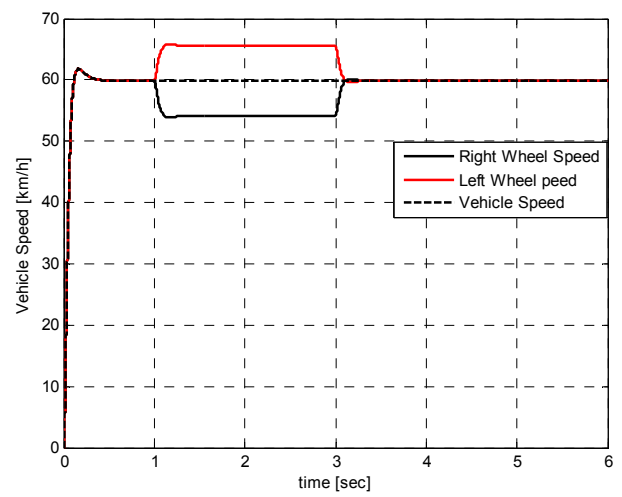

Fig. 18 Vehicle speed in right turn in curved way

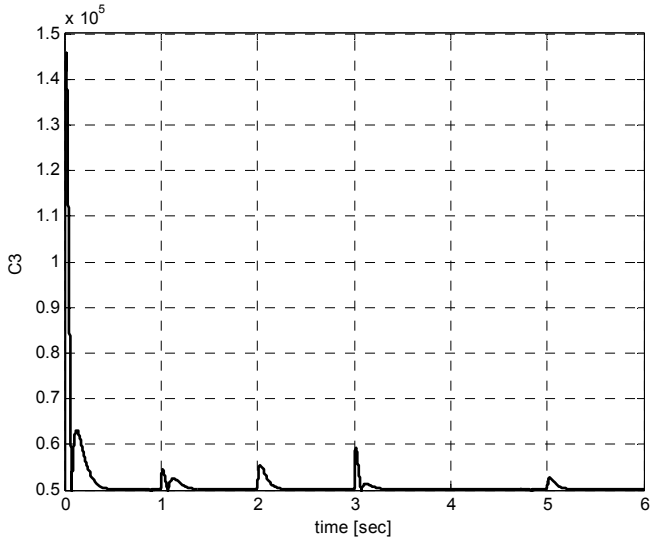

Fig. 19 The adjustment constant fuzzy backstepping

The advantage of this control is its robustness, its capacity to maintain ideal trajectories for two wheels control independently and ensure good disturbances rejections with no overshoot and stability of vehicle perfected ensured with the speed variation and less error speed. To compare the effect of disturbances on the vehicle speed in the cases of two types of control, fig. 19 shows the system response in two cases (Fuzzy-Backstepping, and Backstepping control).

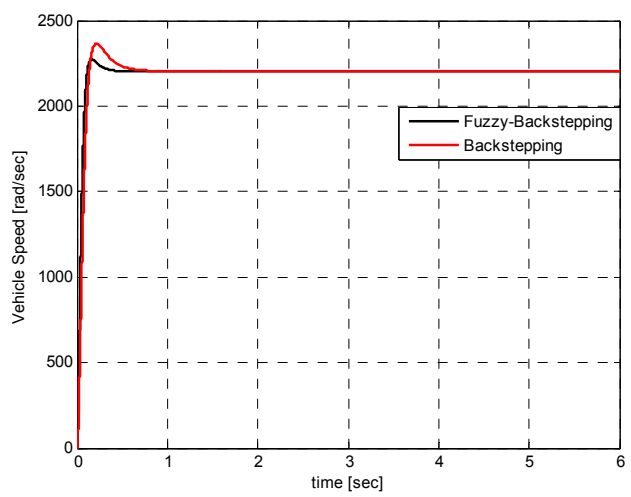

Fig. 20 Comparison of the vehicle speed for the two controllers

\section{CONCLUSION}

The research outlined in this paper has demonstrated the feasibility of an improved vehicle stability which utilizes two independent back drive wheels for motion by using the fuzzy-Backstepping control. This paper proposes an 'independent machine' control structure applied to a propulsion system ensuring by the electronic differential. The results obtained by simulation show that this structure permits the realization of the robust hybrid control based on Fuzzy inference system, with good dynamic and static performances for the multi-converters/multi-machines propulsed system.

The proposed Fuzzy-Backstepping controller improves the driving wheels' speeds control with high accuracy either in flat roads or curved ones. The disturbances do not affect the performances of the driving motors and the hybrid control gives good dynamic characteristics of the traction chain. 


\section{REFERENCES}

[1] HARTANI, K. - BOURAHLA, M. -MILOUD, Y.:"Electric Vehicle Stability Improvement Based on Anti-Skid Control Using Behaviour Model Control",Electro motion - Cluj Napoca,Vol. 14, Part 4, pp. 209-171.

[2] NASRI, A. - HAZZAB, A. - BOUSSERHANE, I. K. - HADJERI, S.- SICARD, P.:' Two Wheel Speed Robust Sliding Mode Control For Electric Vehicle Drive', Serbian Journal of Electrical Engineering , Vol 5, No 2, November 2008, pp. 199-216.

[3] YOICHI, H. - YASUSHI, T. - YOSHIMASA, T.: Traction control of electric vehicle: Basic experimental results using the test EV "UOT Electric march". IEEE Transactions on Industry Applications. September/October 1998. Vol. 34, No. 5. pp. 11311138.

[4] TRIGUI, R.:"Asynchronous Motorization for Electric Vehicle" $\mathrm{PhD}$ Thesis in Electrical Engineering, National Institute of Polutechnics of Lorraine, Nancy, Paris, 1997.

[5] CHEN, C. Y. - HSENG, S. T. LI. - YEH, Y. C.:" EPbased ki-nematic control and adaptive fuzzy slidingmode dynamic control for wheeled mobile robots" , Information Sciences 179 (2009) pp. 180-195 .

[6] HAZZAB, A. - BOUSSERHANE, I. K.-KAMLI, M. - RAHLI, M.: "New Adaptive fuzzy PI-Sliding Mode Con-troller for Induction Machine Speed Control". Third IEEE International Conference on Conference on Systems, Signals \& Devices SSD'05, Tunisia, (2005).

[7] KHESSAM, M.:"Fuzzy controllers optimized by ant algorithms for the control of electric vehicle", Doctoral thesis, LMD University of Tahri Mohamed Bechar 2016.

[8] BENASKEUR, A. R, (2000).: "Aspects de l'Application du Backstepping Adaptatif a' La Commande Décentraliseée des Syste'mes NonLine'aires", PhD thesis, Department of Electrical and Computer Engineering, Laval University, Quebec.

[9] KANELLAKOPOULOS, I. - KOKOTOVIC, P. V. MORSE, A. S. (1991).: "Systematic design of adaptive controller for feedback linearizable systems",IEEE Trans. Auto. Control, Vol. 36 No. 11,pp. 1241-53.

[10] KRSTIC, M. - KANELLAKOPOULOS, I. KOKOTOVIC, P. V. (1995).: Nonlinear and Adaptive Control Design, Wiley, New York, NY.

[11] LIN, F. J. - LEE, C. - C.(2000).:“Adaptive backstepping control for linear induction motor drive to track periodic references", IEE Proc. Electr. Power Appl., Vol. 147 No. 6, pp. 449-58

[12] POZO, F. - IKHOUANE, F. - RODELLAR, J. (2008).: "Numerical issues in backstepping control sensitivity and parameter tuning", Journal of the Franklin Institute, Vol. 345, No. 8, pp. 891-905.

[13] HUANG, C. - I., CHEN, K. - L.,LEE, H. - T. AND FU, L. - C. (2002), "Nonlinear adaptive backstepping motion control of linear induction motor",Proceedings of the American Control Conference, Anchorage, AK, USA, May 8-10, pp. 3099-104.

[14] DERDIYOK, M. K. - GUVEN, H. - RAHMAN, N. - INANE, L. XU.: Design and Implementation of New Sliding-Mode Observer for Speed-Sensorless Control of Induction Machine,IEEE Trans. on Industrial Electronics, Vol. 49, No. 5, Oct. 2002, pp. $1177-1182$.

[15] ZHOU, J. - WANG, Y. (2005).: "Real-time nonlinear adaptive backstepping speed control for a PM synchronous motor",Control Engineering Practice, Vol. 13, pp. 1259-69.

[16] KHOUCHA,F. - MAROUANI, K. - KHELOUI, A. - ALIOUANE, K.: Experimental Performance Analysis of Adaptive Flux and Speed Observers for DirectTorque Control of Sensorless Induction Machine Drives, IEEE 35 Th Power Electronics Specialists Conference PESC2004, Vol. 6, Aachen, Germany, June 2004, pp. 2678 - 2683.

[17] GAIR, S. and al.: Electronic differential with sliding mode controller for a direct wheel drive electric vehicle, in Proceedings of IEEE ICM"04, pp. 98-103, June2004.

[18] HADDOUN, A. - BENBOUZID, M. E. H. DIALLO, D. - ABDESSEMED, R. - GHOUILI, J. - SRAIRI, K.: Sliding Mode Control of EV Electric Differential System, in ICEM06, Chania: Greece2006 .

Received April 27, 2018, accepted April 17, 2019

\section{BIOGRAPHIES}

Ahmed Laguidi was born in Bechar, Algeria, on 07.02. 1969. He received the Engineer degree in Electrotechnics, the Magister degree of Electrical engineering from University of Tahri Mohammed, Bechar, in 2006, 2011, respectively. He iscurrently a Research member Laboratory Laboratory of Command,Analyse and Optimisation of Electro-Energetic System Department of Electrical engineering, of Tahri mohammed, Bechar University. His main research activity is focused on electric machine drive systems, power electronics and process control.e-mail address: laguidiahmed@yahoo.com

Abdeldjebar Hazzab was born in Bechar, Algeria, on 22.01.1971. received his State Engineer, M.S, and PhD degrees in Electrical Engineering from the Electrical Engineering Institute of The University of Sciences and Technology of Oran (USTO), Algeria in 1995, 1999, and 2006, respectively. He is currently a Professor of Electrical Engineering at the University of Bechar (Algeria), where 
he has been the Director of the Research Laboratory of Command, Analyses, and Optimization of ElectroEnergetic Systems since 2009. His research interests include power quality, modeling, modern controller and observer design for nonlinear systems, control of power electronics and multidrive systems, control of power electronics, multidrive systems and electrical vehicle, and adaptive control and nonlinear systems diagnostic, adaptive control, neural networks and fuzzy logic systems.

Othmane Boughazi was born in Bougtob, El bayadh, Algeria, on 09.03.1977. He received the Engineer degree in Electrotechnics, the Magister degree and Doctorat of Electrical engineering from University of Tahri
Mohammed, Bechar, in 2006, 2010 and 2016, respectively. Heiscurrently a Research member Laboratory Smart Grids \& renewlable Energies Department of Electrical engineering, of Tahri Mohammed, Bechar University. Hismain research activity is focused on electric machine drive systems, power electronics and process control.

Mohamed Habbab was born in Relizane, Algeria, on 16.03.1969. He received the state engineer degree in electronic engineering in 1994 from the University of Sciences and Technology of Oran (USTO), Algeria the M.Sc. degree from the University of Bechar. He's currently preparing his Ph.d. degree in electronic engineering. 